\section{Inflammatory pseudotumors after stem cell transplantation}

\author{
Asli Tufan, Gulistan Bahat \\ Division of Geriatrics, Department \\ of Internal Medicine, Istanbul Medical \\ School, Turkey
}

\section{Abstract}

Inflammatory pseudotumors (IPT) are rare tumors that occur in various organs and tissues. The clinical picture varies from the more frequent benign lesions to rare malignant tumors with distant metastases. IPTs associated with hematopoietic stem cell transplantation (HSCT) is rarely reported. In this article, we review the reports of IPT after HSCT. We also review the possible factors involved in the pathogenesis. IPT may be rare but they are a potentially serious complication of HSCT. A knowledge of these entities and insistence on a definitive biopsy of mass lesions in the post-HSCT period can avoid unnecessary treatment such as radical surgery, chemotherapy or radiotherapy.

\section{Introduction}

Inflammatory pseudotumors (IPTs) are rare and usually benign tumors but difficult to distinguish from malignant tumors with diagnostic techniques. They may be asymptomatic or may present with inflammatory or mass-related symptoms and signs. ${ }^{1}$ The pathogenesis is still not clear. IPT of different organs associated with hematopoietic stem cell transplantation (HSCT) has been reported in only eight patients to date..$^{2-8}$

\section{Review of previous literature}

Fangusaro et $a .^{2}{ }^{2}$ reported the first cases of IPT after HSCT in two pediatric patients. The first case was a boy aged 8 years with acute lymphocytic leukemia (ALL) who achieved remission after second-line chemotherapy. Following conditioning with high-dose cytosine arabinoside and total body irradiation (TBI), he underwent allogeneic HSCT. The major early complications were acute skin and gut graft versus host disease (GVHD). Liver IPT appeared at 28 months, presenting with abdominal distention. After lobectomy with complete resection of the mass, patient remained in good clinical condition postoperatively. The case 2 was a boy aged 3 years with neuroblastoma. Following conditioning with carboplatin, etoposide, melphalan and TBI, he received an autologous HSCT. He first developed an esophageal stricture due to radiation therapy 2 years afterwards and underwent balloon dilatation. A mass detected within the esophagus 4 months later. After surgical resection, the mass was diagnosed as IPT. The patient remained in good clinical condition postoperatively and had no recurrence.

The case 3 was a 23 year old woman who underwent allogeneic HSCT for ALL. ${ }^{3}$ Renal IPT appeared at 10 months, presenting with abdominal distention. Unilateral nephrectomy was performed without complication.

The case 4 was a 50 year old woman who had undergone allogeneic HSCT for acute myeloid leukemia (AML). Conditioning was with $120 \mathrm{mg} / \mathrm{kg}$ cyclophosphamide (CY) and total body irradiation (TBI). After19 months, she had a sensory disturbance that involved the left side of the body. A mass detected on cranial imaging. ${ }^{4}$ Tumor was resected but she died from an fungal infection 5 months after IPT diagnosis.

Case 5 was a man aged 42 years who underwent allogeneic HSCT for AML. ${ }^{5}$ Conditioning was with $16 \mathrm{mg} / \mathrm{kg}$ busulfan and $120 \mathrm{mg} / \mathrm{kg} \mathrm{CY}$. The patient had a dyspnea and GVHD at 12 months. Pulmonary imaging showed lung IPT. High-dose steroid treatment provided resolution of both pulmonary and GVHD symptoms.

Case 6 was a 32 year old man. He developed bladder IPT after allogeneic HSCT for AML. ${ }^{6}$ Conditioning was with busulfan $4 \mathrm{mg} / \mathrm{kg} /$ day, orally on days -7 to -4 , and cyclophosphamide (CY) $60 \mathrm{mg} / \mathrm{kg} /$ day, i.v. on days -3 and -2 . Hyperhydration and mesna $(30 \mathrm{mg} / \mathrm{kg}$, four times a day) during CY infusion was given in order to prevent CY-induced hemorrhagic cystitis (HC). The patient experienced dysuria with macroscopic hematuria andclots in the urine on day -1 . Urinary system ultrasonography on day +14 revealed a dense echogenic lesion with irregular borders like a clot. Cystoscopy doneand a mass of clot was found in the bladder on day +17 . After removal of clot, there was no active bleeding. During follow-up, on day +71 a mobile echogenic mass in the bladder detected. Complete transurethral resection (TUR) of the mass was performed. After 2 months later the tumor recurred but smaller than the initial lesion which was treated by TUR, too.

Case 7 was a Japanese woman aged 36 years with chemorefractory adult T-cell leukemia (ATL). ${ }^{7}$ There were no human leukocyte antigen-identical sibling donors, and therefore unrelated umbilical cord blood was arranged. Approximately 18 months post transplant, the patient developed a cough, slight fever and malaise. Slight anemia and thrombocytosis also appeared. Computer tomography of the chest revealed a solid mass. The pathologic
Correspondence: Asli Tufan, Istanbul University, Istanbul Medical School, Department of Internal Medicine, Capa, 34390, Istanbul, Turkey.

Tel.: +90.212.4142.0003.1478 - Fax: +90.212.532.4208.

E-mail: aslitufan@yahoo.com

Key words: Inflammatory pseudotumors; stem cell transplantation.

Contributions: the authors contributed equally.

Conflict of interest: the authors declare no potential conflict of interest.

Received for publication: 4 February 2015.

Revision received: 1 Juny 2015.

Accepted for publication: 22 June 2015.

This work is licensed under a Creative Commons Attribution NonCommercial 3.0 License (CC BYNC 3.0).

(C) Copyright A. Tufan and Gulistan Bahat, 2015

Licensee PAGEPress, Italy

Hematology Reports 2015; 7:5848

doi:10.4081/hr.2015.5848

findings appeared to be compatible with IPT. Anti-inflammatory medication improved the clinical symptoms, and the mass lesion exhibited no obvious change, while the ATL remained stable.

Case 8 was a boy aged 10 was diagnosed with B-precursor ALL. He was treated with a regimen of intensive chemotherapy and declared in remission. He was diagnosed with bone marrow relapse two yr later, and after he was treated with a second course of chemotherapy, he was then referred for bone marrow transplantation from an unrelated donor . Then reported slowly developing dyspnea on exertion and cough around seven months post- allogeneic hematopoietic cell transplantation. After 8 months he was diagnosed as having an endobronchial tumor based on imaging, subtotal resection was performed and histology confirmed ALK-positive submucosal spindle-shaped cells with infiltrative cells, compatible with IPT. After this procedure there was no tumor regrowth. ${ }^{8}$

\section{Discussion}

The clinical picture of IPTs are generally varies from the more frequent benign lesions to rare tumors, which are multifocal and prone to recurrence (Table 1). ${ }^{6-8}$

Local and vascular invasions are usually seen. IPTs may rarely undergo malignant transformation, occasionally with distant metastases. ${ }^{9-11}$ Coffin et al. emphasized their neoplastic nature and proposed the use of the 
Table 1. Inflammatory pseudotumor of different organs in patients following hematopoietic stem cell transplantation.

\begin{tabular}{|c|c|c|c|c|c|c|c|c|c|}
\hline Case & Age & Sex & $\begin{array}{l}\text { Type } \\
\text { of HSCT }\end{array}$ & $\begin{array}{l}\text { Primary } \\
\text { disease }\end{array}$ & $\begin{array}{l}\text { Time of IPT } \\
\text { after HSCT }\end{array}$ & $\begin{array}{l}\text { Involved } \\
\text { organ }\end{array}$ & $\begin{array}{l}\text { Possible factor } \\
\text { for IPT }\end{array}$ & Therapy & Outcome \\
\hline 1 & 8 & M & Allogeneic & ALL & 28 months & Liver & $\mathrm{CT}+\mathrm{TBI}+$ immunosuppression & Hepatic lobectomy & Alive \\
\hline 2 & 3 & M & Autologous & NBL & 2.5 years & Esophagus & CT+TBI & Resection & Alive \\
\hline 3 & 23 & $\mathrm{~F}$ & Allogeneic & ALL & 10 months & Kidney & CT+immunosuppression & Nephrectomy & Alive \\
\hline 4 & 50 & $\mathrm{~F}$ & Allogeneic & AML & 19 months & Brain & CT+immunosuppression & Resection+brain radiation & Died \\
\hline 5 & 42 & M & Allogeneic & AML & 12 months & Lung & $\begin{array}{l}\text { CT+immunoSuppression+ } \\
\text { pulmonary aspergillosis }\end{array}$ & Partial resection & Alive \\
\hline 6 & 32 & M & Allogeneic & AML & 3 months & Bladder & $\begin{array}{l}\text { CT+immunosuppression+ } \\
\text { hemorrhagic cystitis }\end{array}$ & Resection & Alive \\
\hline 7 & 36 & $\mathrm{~F}$ & Allogeneic & ATL & 18 months & Lung & CT+TBI+ immunosuppression & Anti-inflammatory medication & Alive \\
\hline 8 & 10 & M & Allogeneic & ALL & 7 months & Lung & CT+TBI+ immunosuppression & Partial resection & Alive \\
\hline
\end{tabular}

term inflammatory myofibroblastic tumor rather than inflammatory pseudotumor. The pathologic feature of IPTs is a proliferation of spindle cells associated with a variably dense polymorphic infiltrate of mononuclear inflammatory cells (e.g., lymphocytes, plasma cells, histiocytes, and occasional eosinophils). ${ }^{1,10}$

The lung is the most common site for involvement, but lesions may be detected on extra-pulmonary locations. Coffin et al. described 84 patients in the largest IPT series to date. But patients from his reports of IPT are not after HSCT. The presenting complaints of patients are fever, weight loss and pain, together with mass related symptoms of an inflammatory process. ${ }^{1}$ Thrombocytosis, anemia, elevation of erythrocyte sedimentation rate and polyclonal hypergamma globulinemia. The involvement sites were mostly the abdomen, retroperitoneum and pelvis, followed by head, neck, upper respiratory tract, trunk and extremities. The pathogenesis and relationship to HSCT is still unclear and several factors are implicated.

Infection has been accepted as a factor for IPT development. Hepatitis C virus, human immunodeficiency virus, Epstein Barr virus, bacterial, fungal and mycobacterial infections have been reported to IPT. ${ }^{1,10}$

A reactive process for IPT is suggested. ${ }^{10}$ Maybe a result from an unusual response to noninfectious agents such as trauma or surgery. ${ }^{9-12}$ Among the IPT cases in the post-HSCT period, the esophageal IPT developed after the stricture in patient 2 . Patient 6 developed IPT after a cystoscopy. It will be a reactive process in response to a noninfectious agent. ${ }^{13-16}$

Chemotherapy and radiotherapy are also potential predisposing factors. ${ }^{10,17-22}$ Use of CY was mentioned as associated with bladder IPT in the literature. ${ }^{10-13}$ All of the patients with IPT after HSCT were given high-dose chemotherapy and some also received TBI.

Immunosuppression and GVHD are the two factors most likely to be associated with IPTs that develop after HSCT., ${ }^{2,5}$ The immunosuppression may be an important factor. With GVHD, chronic stimulation of the cellular immune system might be the major factor. ${ }^{23,24}$ Although IPTs are rare tumors, they can have a significant role on patient morbidity after HSCT. They generally have a much better prognosis than a carcinoma.

Increased morbidity may derive from its site in a vital organ or from aggressive treatment given due to a misdiagnosis of malignancy. ${ }^{1,13}$ It is difficult to distinguish IPT from malignant tumors with imaging techniques but time of the lesion is a very important data. IPTs occur earlier in the post-transplant period ranging between 3 months and 2.5 years after SCT. Secondary malignancies occur as later transplant complications due to irradiation and anticancer agents, which are diagnosed at a median of 4.6 years. ${ }^{22-25}$

Definitive histologic evaluation of the mass must be done. So we can avoid unnecessary treatment-related complications.

In summary, although IPTs are rare, it will be a serious complication of HSCT and seen in many organs. Unexplained inflammatory symptoms/signs or any mass lesion in the postHSCT period of a patient must be considered carefully. Definitive histologic evidence is essential in their diagnosis and differentiation from other malignant tumors.

\section{References}

1. Coffin CM, Watterson J, Priest JR, Dehner LP. Extrapulmonary inflammatory myofibroblastic tumor (inflammatory pseudotumor). A clinicopathologic and immunohistochemical study of 84 cases. Am J Surg Pathol 1995;19:859-72.

2. Fangusaro J, Klopfenstein K, Groner J, et al. Inflammatory myofibroblastic tumor following hematopoietic stem cell trans- plantation: report of two pediatric cases. Bone Marrow Transplant 2004;33:103-7.

3. Ogura K, Ikeda T, Kobayashi S, et al. Inflammatory pseudotumor of the kidney arising afterunrelatedbone marrow transplantation. Bone Marrow Transplant 2004;34:831-2.

4. Tsutsumi Y, Kanamori H, Kawamura T, et al. Inflammatory pseudotumor of the brain following hematopoietic stem cell transplantation. Bone Marrow Transplant 2005;35:1123-4.

5. Priebe-Richter C, Ivanyi $\mathrm{P}$, Buer J, et al. Inflammatory pseudotumor of the lung following invasive aspergillosis in a patient with chronic graftvs.-host disease. Eur J Haematol 2005;75:68-72.

6. Baha G, Kalayoglu-Besisik S, Ozturk S, et al. Inflammatory pseudotumor following hematopoietic stem cell transplantation: a new case and review of the literature. Bone Marrow Transplant 2007;40:915-8.

7. Nomura S, Ishii K, Shimizu M, et al. Inflammatory pseudotumor following cord blood transplantation for adult T-cell leukemia. Bone Marrow Transplant 2008;42:493-4.

8. Fujino H, Park YD, Uemura $S$, et al. An endobronchial inflammatory myofibroblastic tumor in a 10 -yr-old child after allogeneic hematopoietic cell transplantation. Transplant 2014;18:5.

9. Dishop MK, Warner BW, Dehner LP et al. Successful treatment of inflammatory myofibroblastic tumor with malignant transformation by surgical resection andchemotherapy. J Pediatr Hematol Oncol 2003;25:153-8.

10. Coffin CM, Humphrey PA, Dehner LP. Extrapulmonaryinflammatory myofibroblastic tumor. Semin Diagn Pathol 1998;15:85-101.

11. Morotti RA, Legman MD, Kerkar N, et al. Pediatric inflammatory myofibroblastic tumor with late metastasis to the lung: 
case report and review of the literature. Pediatr Dev Pathol 2005;8:224-9.

12. Pungpapong S, Geiger XJ, Raimondo M. Inflammatory myofibroblastic tumor presenting as a pancreatic mass: a case report andreview of the literature. JOP 2004;5:360-7.

13. Harik LR, Merino C, Coindre JM, et al. Pseudosarcomatous myofibroblastic proliferations of the bladder: a clinicopathologic study of 42 cases. Am J Surg Pathol 2006;30:787-94.

14. Jackman SV, Schulam PG, Schoenberg M. Pseudotumor ofthe bladder: a late complication of inguinal herniorrhaphy. Urology 1997;50:609-11.

15. Wanibuchi $\mathrm{H}$, Iwata $\mathrm{H}$, Washida $\mathrm{H}$, et al. A case report of inflammatory pseudotumor of the urinary bladder. Osaka City Med J 1995;41:31-9.

16. Serra J, Matias-Guiu X, Calabuig R, et al. Surgical gauze pseudotumor. Am J Surg 1988;155:235-7.
17 Tan KB, Thamboo TP, Raju GC. Xanthomatous pseudotumor.An unusual postchemotherapy phenomenon in breast cancer. Arch Pathol Lab Med 2003;127:73941.

18. Isobe $\mathrm{H}$, Nishi $\mathrm{Y}$, Fukutomi $\mathrm{T}$, et al. Inflammatory pseudotumor of the liver associated with acute myelomonocytic leukemia. Am J Gastroenterol 1991;86:23840.

19. Remberger K, Weiss M, Gokel JM, et al. Inflammatory pseudotumor of the pancreas with persistent hyper-insulinemia and hypoglycemia following long term pancreatic transplantation. Verh Dtsch Ges Pathol 1987;71:328-32.

20. Lykavieris P, Fabre M, Waguet J, Bernard 0. Inflammatorypseudotumor after liver transplantation. J Pediatr Gastroenterol Nutr 2000;31:309-12.

21. Lykavieris P, Fabre M, Pariente D, et al. Clostridium difficile colitis associated with inflammatory pseudotumor in a liver transplant recipient. Pediatr Transplant 2003;7:76-9.

22. Oota $S$, Shibuya H, Hamagaki M, et al. Oral pseudotumor: benign polypoid masses following radiation therapy. Cancer 2003;97:1353-7.

Fujimaki K, Maruta A, Yoshida M, et al. Immune reconstitution assessed during five years after allogeneic bone marrow transplantation. Bone Marrow Transplant 2001;27:1275-81.

24. Sugita K, Soiffer RJ, Murray C, et al. The phenotype and reconstitution of immunoregulatory $\mathrm{T}$ cell subsets after $\mathrm{T}$ cell-depleted allogeneic and autologous bone marrow transplantation. Transplantation 1994;57:1465-73.

25. Ades L, Guardiola P, Socie G. Second malignancies after allogeneic hematopoietic stem cell transplantation: new insight and current problems. Blood Rev 2002;16:135-46. 